\title{
Comparing tobacco use among incoming recruits and military personnel on active duty in the United States
}

\author{
Michael C Chisick, Forrest R Poindexter, Andrew K York
}

\begin{abstract}
Objective-To compare the tobacco use profile of recruits with that of military personnel on active duty to determine whether the military environment in some way induces service members to initiate tobacco use.

Design and setting-Cross-sectional survey of United States armed forces active duty and recruit personnel in 1994-95. Subjects-2711 military recruits and 4603 military personnel on active duty.

Main outcome measures-Comparative cigarette smoking and smokeless tobacco use prevalence between recruits and personnel on active duty controlling for age, sex, and race. Impact of demographic factors on the odds of smoking or using smokeless tobacco.

Results-Increases in tobacco use in American military personnel occurred exclusively in men. The highest tobacco use resided with white men on active duty (43\% cigarette smoking; $24 \%$ smokeless tobacco use) and represents a doubling of tobacco use seen among white male recruits. Among non-white men, tobacco use increased 2-4 times between recruits and personnel on active duty.

Conclusions-Efforts to reduce tobacco use by American military personnel on active duty should focus more on discouraging the initiation of tobacco use. (Tobacco Control 1998;7:236-240)
\end{abstract}

Keywords: tobacco use, military personnel, United States

\section{Introduction}

Historically, tobacco use by American military personnel on active duty has greatly exceeded that found in the civilian population. Roughly two decades ago, the first Department of Defense (DoD) survey of health-related behaviours reported an overall cigarette smoking rate of $51 \%$ for military personnel on active duty. According to the most recent DoD survey (1995), the overall cigarette smoking rate for service members on active duty had declined to $33 \%$. This decline has been attributed to an increased emphasis on smoking cessation and prevention in the military. ${ }^{1}$

Comparing the cigarette smoking rate among service members on active duty to that among the civilian population requires standardising the data to control for sociodemographic differences between the two populations. $^{2}$ When this is done, overall cigarette smoking prevalence in the military population (33\%) appears to compare favourably with the civilian population $(31 \%) .{ }^{1}$ However, overall population comparisons can obscure important differences between subgroups within those populations. For example, results from the 1995 DoD survey also show that, depending on branch of service, 33-45\% of 18-25 year old military personnel on active duty smoke cigarettes, compared with $36 \%$ of similarly aged civilians. ${ }^{1}$

One limitation of the DoD surveys is that their samples did not include military recruits, that is, individuals newly ascended into the military from civilian life. It would be unwise to assume that military recruits possess traits similar to those found in civilian tobacco surveys. Military recruits are a self-selected subgroup that differ from the general civilian population in many ways. For one, they are generally healthier, having met physical fitness standards for entry into military service. In addition, the services prefer to recruit individuals with at least a high-school education, yet few college-bound prospects enter the military for enlisted service.

Given the potentially different demographic profile of military recruits and the general civilian population, it is unknown how the tobacco use profile of military recruits compares with that of service members on active duty. Knowing the comparative tobacco use profile of military recruits versus personnel on active duty is important for determining whether the existing tobacco use profile of personnel on active duty is merely a reflection of the tobacco use behaviours that recruits bring with them when they enter the military, or whether events subsequent to enlistment play a role. Such knowledge will give some indication of whether exposure to the military environment in some way induces service members to begin using tobacco. The military may well be contributing to its tobacco use problem by its co-existing, contradictory policies on tobacco. Despite DoD-wide smoking cessation programmes, smoking bans in the workplace, and bans on tobacco use during recruit basic training, tobacco products are still readily available in military stores at a substantial price discount compared with the civilian community. Knowing the comparative tobacco use profile of military recruits versus personnel on active duty will also help determine whether current 
Table 1 Unweighted distribution of recruit $(R)$ and active duty (AD) samples, by age, sex, and race

\begin{tabular}{|c|c|c|c|c|c|c|}
\hline \multirow[b]{2}{*}{ Age (years) } & \multicolumn{2}{|c|}{ Whites } & \multicolumn{2}{|c|}{ Blacks } & \multicolumn{2}{|c|}{ Others } \\
\hline & $R$ & $A D$ & $R$ & $A D$ & $R$ & $A D$ \\
\hline \multicolumn{7}{|l|}{ Men } \\
\hline $18-19$ & 701 & 157 & 198 & 35 & 118 & 18 \\
\hline $20-24$ & 566 & 2128 & 190 & 502 & 116 & 286 \\
\hline $25-29$ & 56 & 459 & 17 & 127 & 15 & 74 \\
\hline $30-34$ & 10 & 71 & 4 & 26 & 6 & 22 \\
\hline Total & 1333 & 2815 & 409 & 690 & 255 & 400 \\
\hline \multicolumn{7}{|l|}{ Women } \\
\hline $18-19$ & 221 & 24 & 60 & 8 & 48 & 2 \\
\hline $20-24$ & 216 & 311 & 67 & 138 & 34 & 46 \\
\hline $25-29$ & 36 & 87 & 13 & 42 & 2 & 15 \\
\hline $30-34$ & 8 & 15 & 6 & 7 & 3 & 3 \\
\hline Total & 481 & 437 & 146 & 195 & 87 & 66 \\
\hline
\end{tabular}

military tobacco control policies and programmes, which emphasise tobacco cessation, are adequate or whether a more expanded strategy, including tobacco interdiction, is indicated.

Only one previous study has explored the comparative tobacco use profiles of military recruits and personnel on active duty. This 1988 survey of male navy personnel $^{3}$ has several serious design limitations. First, the authors did not adequately describe their sampling strategy. They merely described the source and size of their recruit and active duty samples, but not how either was selected. Nor did the authors mention non-response. It is unclear whether either the recruit or active duty samples were random and representative of the populations from which they were drawn or whether they were convenience samples. Second, the authors chose an inappropriate comparison sample by including officers and by including enlisted personnel beyond the age range of recruits in its active duty sample. Third, the age and race composition of the comparison active duty sample was not standardised to that of the recruit sample so that overall smoking prevalence rates between the two groups could be directly compared. These limitations could introduce serious bias into the findings.

Our study overcomes these limitations and expands the scope of the research to include smokeless tobacco (SLT), service members from the other armed services beyond the navy, and women.

\section{Methods}

The data for this study come from the 1994 Tri-Service Comprehensive Oral Health Survey, a 30-site, cross-sectional survey of American army, navy, marine, and air force active duty and recruit personnel. ${ }^{4}$ We drew the recruit sample $(\mathrm{n}=2711)$ at recruit in-processing centres using stratified, systematic random sampling. Personnel on active duty ( $\mathrm{n}=15915$ ) were selected using stratified, multistage random sampling and were surveyed at military dental clinics. Women and minorities were oversampled. All of the recruit sample and $82 \%$ of the active duty sample $(\mathrm{n}=$ 13 050) participated in the survey.

All participants, whether recruits or personnel on active duty, completed a self-administered, electronic questionnaire ${ }^{5}$ that included queries on cigarette smoking and SLT use. For both groups, the questions were worded identically and were administered in an identical format. We defined a cigarette smoker as someone who answered "yes" to the question: "Do you smoke cigarettes now?". We defined a SLT user as someone who answered "yes" to either of the following questions: "Do you use snuff now?" and "Do you use chewing tobacco now?". Data were collected on the recruit sample between February and July 1994 during in-processing, not during basic training. In-processing occurs during the first three days following the recruit's arrival at a basic training centre. Data were collected on the active duty sample between April 1994 and January 1995.

To make the two groups comparable in demographic composition, we removed from the active duty sample all officers, all personnel over 34 years of age, and all personnel with greater than five years of military service. This created a final active duty sample of 4603. A comparison of the two unweighted samples stratified by age, sex, and race is presented in table 1 .

We did two types of analysis. First, we compared tobacco use between active duty and recruit military personnel after stratifying the weighted samples by age, sex, and race. We weighted the data to reflect the respective total populations of $18-34$ year old recruits and personnel on active duty-101072 and 711534 , respectively. We calculated point estimates and $95 \%$ confidence intervals (CIs). For all

Table 2 Proportion of 18-34 year old recruits $(R)$ and military personnel on active duty $(A D)$ who smoke, by age, sex, and race

\begin{tabular}{|c|c|c|c|c|c|c|c|c|c|c|c|c|}
\hline \multirow[b]{3}{*}{ Age (years) } & \multicolumn{4}{|c|}{ Whites } & \multicolumn{4}{|c|}{ Blacks } & \multicolumn{4}{|c|}{ Others } \\
\hline & \multicolumn{2}{|l|}{$R$} & \multicolumn{2}{|l|}{$A D$} & \multicolumn{2}{|l|}{$R$} & \multicolumn{2}{|l|}{$A D$} & \multicolumn{2}{|l|}{$R$} & \multicolumn{2}{|l|}{$A D$} \\
\hline & $(\%)$ & $95 \% C I$ & $(\%)$ & $95 \% C I$ & $(\%)$ & $95 \% C I$ & $(\%)$ & $95 \% C I$ & $(\%)$ & $95 \% C I$ & $(\%)$ & $95 \% C I$ \\
\hline \multicolumn{13}{|l|}{ Men } \\
\hline $18-19$ & 20.3 & $17.3-23.3$ & 42.0 & $34.3-49.7$ & 4.5 & $1.6-7.4$ & 25.9 & $11.4-40.4$ & 9.3 & $4.1-14.5$ & 28.6 & $7.7-49.5$ \\
\hline $20-24$ & 21.4 & $18.0-24.8$ & 36.8 & $34.8-38.8$ & 7.0 & $3.4-10.6$ & 15.9 & $7.9-23.9$ & 14.8 & $8.3-21.3$ & 24.5 & $19.5-29.5$ \\
\hline $25-29$ & 25.8 & $14.4-37.2$ & 32.3 & $28.0-36.6$ & 0 & 0 & 15.0 & $8.8-21.2$ & 9.8 & $-5.2-24.8$ & 25.0 & $15.1-34.9$ \\
\hline $30-34$ & $\star \star$ & * & 43.5 & $32-55.0$ & $\star$ & $\star$ & 23.0 & $6.9-39.1$ & $\star$ & $\star$ & 21.4 & $4.3-38.5$ \\
\hline Total & 21.1 & $18.9-23.3$ & 42.8 & $41.0-44.6$ & 5.4 & $3.2-7.6$ & 20.4 & $17.4-23.4$ & 11.5 & $7.6-15.4$ & 26.4 & $22.1-30.7$ \\
\hline \multicolumn{13}{|l|}{ Women } \\
\hline $18-19$ & 28.7 & $22.7-34.7$ & 15.6 & $31.3-30.1$ & 3.3 & $-1.2-7.8$ & $\star$ & * & 28.8 & $16.0-41.6$ & $\star$ & $\star$ \\
\hline $20-24$ & 24.6 & $18.9-30.3$ & 30.8 & $25.7-35.9$ & 13.2 & $5.1-21.3$ & 6.8 & $2.6-11.0$ & 13.4 & $2.0-24.8$ & 15.4 & $5.0-25.8$ \\
\hline $25-29$ & 26.8 & $12.3-41.3$ & 38.5 & $28.3-48.7$ & $\star$ & $\star$ & 17.9 & $6.3-29.5$ & $\star$ & $\star$ & 41.8 & $16.8-66.8$ \\
\hline $30-34$ & $\star$ & $\star$ & 12.2 & $-4.4-28.8$ & $\star$ & $\star$ & $\star$ & $\star$ & $\star$ & * & $\star$ & $\star$ \\
\hline Total & 26.3 & $22.4-30.2$ & 24.0 & $20.0-28.0$ & 9.9 & $5.1-14.7$ & 6.8 & $3.3-10.3$ & 26.2 & $17.0-35.4$ & 36.0 & $24.4-47.6$ \\
\hline
\end{tabular}

*Insufficient sample size for stable estimate.

$\mathrm{CI}=$ confidence intervals. 
Table 3 Proportion of 18-34 year old recruits $(R)$ and military personnel on active duty (AD) who use smokeless tobacco, by age, sex, and race

\begin{tabular}{|c|c|c|c|c|c|c|c|c|c|c|c|c|}
\hline \multirow[b]{3}{*}{ Age (years) } & \multicolumn{4}{|c|}{ Whites } & \multicolumn{4}{|c|}{ Blacks } & \multicolumn{4}{|c|}{ Others } \\
\hline & \multicolumn{2}{|l|}{$R$} & \multicolumn{2}{|l|}{$A D$} & \multicolumn{2}{|l|}{$R$} & \multicolumn{2}{|l|}{$A D$} & \multicolumn{2}{|l|}{$R$} & \multicolumn{2}{|l|}{$A D$} \\
\hline & $(\%)$ & $95 \% C I$ & $(\%)$ & $95 \% C I$ & $(\%)$ & $95 \% C I$ & (\%) & $95 \% C I$ & $(\%)$ & $95 \% C I$ & (\%) & $95 \% C I$ \\
\hline \multicolumn{13}{|l|}{ Men } \\
\hline $18-19$ & 11.7 & $9.3-14.1$ & 23.0 & $16.4-29.6$ & 0 & 0 & 0.7 & $-2.1-3.5$ & 2.3 & $-0.4-5.0$ & 9.4 & $-4.1-22.9$ \\
\hline $20-24$ & 10.6 & $8.1-13.1$ & 22.9 & $21.1-24.7$ & 0 & 0 & 1.6 & $0.5-2.7$ & 2.7 & $-0.2-5.6$ & 8.3 & $5.1-11.5$ \\
\hline $25-29$ & 3.4 & $-1.3-8.1$ & 19.6 & $16.0-23.2$ & 8.9 & $-4.6-22.4$ & 3.2 & $0.1-6.3$ & 0 & 0 & 8.1 & $1.9-14.3$ \\
\hline $30-34$ & $\star$ & $\star$ & 19.8 & $10.5-29.1$ & $\star$ & $\star$ & 4.4 & $-3.5-12.3$ & $\star$ & $\star$ & 0 & 0 \\
\hline Total & 10.9 & $9.2-12.6$ & 24.4 & $22.8-26.0$ & 0.5 & $-0.2-1.2$ & 1.3 & $0.5-2.1$ & 2.2 & $0.4-4.0$ & 8.6 & $5.9-11.3$ \\
\hline \multicolumn{13}{|l|}{ Women } \\
\hline $18-19$ & 0.9 & $-0.3-2.1$ & 0 & 0 & 0 & 0 & $\star$ & $\star$ & 0 & 0 & $\star$ & $\star$ \\
\hline $20-24$ & 0 & 0 & 0.9 & $-0.1-1.9$ & 0 & 0 & 0.8 & $-0.6-2.2$ & 0 & 0 & 0 & 0 \\
\hline $25-29$ & 2.6 & $-2.6-7.8$ & 0.9 & $-1.1-2.9$ & $\star$ & $\star$ & 0 & 0 & $\star$ & $\star$ & 0 & 0 \\
\hline $30-34$ & $\star$ & $\star$ & 6.4 & $-6.0-18.8$ & $\star$ & $\star$ & $\star$ & $\star$ & $\star$ & $\star$ & $\star$ & * \\
\hline Total & 0.6 & $-0.1-1.3$ & 0.6 & $-0.1-1.3$ & 2.4 & $-0.1-4.9$ & 0.4 & -0.5 & 0 & 0 & 0 & 0 \\
\hline
\end{tabular}

^Insufficient sample size for stable estimate.

$\mathrm{CI}=$ confidence intervals.

stratified analyses, estimates for cells containing fewer than 15 observations were excluded because the size of these subsamples was too small to provide stable estimates. To compare tobacco use across all age levels for each sex and race subgroup between the two populations, we standardised the demographic profile of the population on active duty to that of the recruit population. ${ }^{2}$

For our second type of analysis, we conducted backwards, stepwise logistic regression analyses on the unweighted samples, using the regression strategy advocated by Hosmer and Lemshow. ${ }^{6}$ We performed all analyses using Stata statistical software.

\section{Results}

Results of our post-stratification analyses for cigarette smoking and SLT use are presented in tables 2 and 3. The highest levels of smoking $(42.8 \%)$ and SLT use $(24.4 \%)$ among $18-34$ year old enlisted military personnel reside with white men on active duty, and represent a doubling of tobacco use found among white male recruits. Between recruits and personnel on active duty, smoking prevalence doubled for non-white/non-black men from $11.5 \%$ to $26.4 \%$, quadrupled for black men from $5.4 \%$ to $20.4 \%$, but remained unchanged for women of all races at roughly $25 \%$ for whites and nonwhites/non-blacks and $10 \%$ for blacks.

Table 4 Proportion of 18-34 year old recruits and military personnel on active duty who smoke cigarettes or use smokeless tobacco, by branch of service

\begin{tabular}{|c|c|c|c|c|c|c|c|c|c|c|c|c|}
\hline \multirow[b]{3}{*}{ Service } & \multicolumn{6}{|c|}{ Smoking } & \multicolumn{6}{|c|}{ Smokeless tobacco (men only) } \\
\hline & \multicolumn{3}{|c|}{ Recruits } & \multicolumn{3}{|c|}{ Active duty } & \multicolumn{3}{|c|}{ Recruits } & \multicolumn{3}{|c|}{ Active duty } \\
\hline & $n$ & $(\%)$ & $95 \% C I$ & $n$ & $(\%)$ & $95 \% C I$ & $n$ & $(\%)$ & $95 \% C I$ & $n$ & $(\%)$ & $95 \% C I$ \\
\hline Army & 535 & 16.0 & $12.9-19.1$ & 2002 & 34.2 & $32.1-36.3$ & 373 & 6.5 & $4.0-9.0$ & 1764 & 19.8 & $18.0-21.6$ \\
\hline Air force & 751 & 6.3 & $4.6-8.0$ & 1261 & 25.9 & $23.5-28.3$ & 563 & 4.5 & $2.8-7.2$ & 1008 & 12.5 & $10.5-15.5$ \\
\hline Marines & 716 & 19.0 & $16.1-21.9$ & 243 & 39.8 & $33.6-46.0$ & 648 & 10.4 & $6.5-14.3$ & 234 & 21.0 & $17.9-24.1$ \\
\hline Navy & 709 & 27.4 & $24.3-30.7$ & 1097 & 33.9 & $31.1-36.7$ & 413 & 9.4 & $6.6-12.2$ & 899 & 13.2 & $11.0-15.4$ \\
\hline
\end{tabular}

Table 5 Statistically significant adjusted odds ratios for smoking by 18-34 year old recruits and military personnel on active duty

\begin{tabular}{|c|c|c|c|c|c|c|c|c|}
\hline & \multicolumn{4}{|c|}{ Recruits } & \multicolumn{4}{|c|}{ Active duty } \\
\hline & \multicolumn{2}{|l|}{ Men } & \multicolumn{2}{|c|}{ Women } & \multicolumn{2}{|l|}{ Men } & \multicolumn{2}{|c|}{ Women } \\
\hline & $O R$ & $95 \% C I$ & OR & $95 \% C I$ & $O R$ & $95 \% C I$ & $O R$ & $95 \% C I$ \\
\hline \multicolumn{9}{|l|}{ Race } \\
\hline White & 1 & NA & 1 & NA & 1 & NA & 1 & NA \\
\hline Black & 0.23 & $0.14-0.36$ & 0.28 & $0.15-0.54$ & 0.33 & $0.26-0.41$ & 0.24 & $0.14-0.40$ \\
\hline Hispanic & NA & NA & NA & NA & 0.48 & $0.35-0.65$ & NA & NA \\
\hline Asians & NA & NA & NA & NA & 1.41 & $0.84-2.38$ & NA & NA \\
\hline Others & 0.56 & $0.37-0.84$ & 0.70 & $0.39-1.26$ & 0.82 & $0.47-1.43$ & 0.55 & $0.29-1.04$ \\
\hline \multicolumn{9}{|l|}{ Service } \\
\hline Army & 1 & NA & 1 & NA & 1 & NA & 1 & NA \\
\hline Air force & 0.28 & $0.18-0.46$ & 0.28 & $0.14-0.55$ & 0.58 & $0.48-0.70$ & 0.61 & $0.39-0.96$ \\
\hline Marines & 1.16 & $0.81-1.66$ & 0.62 & $0.28-1.36$ & 0.69 & $0.50-0.94$ & 0.53 & $0.33-0.86$ \\
\hline Navy & 1.69 & $1.16-2.46$ & 1.65 & $1.04-2.64$ & 0.67 & $0.56-0.81$ & 0.53 & $0.33-0.86$ \\
\hline \multicolumn{9}{|c|}{ Education years } \\
\hline$<12$ & 1 & NA & 1 & NA & 1 & NA & $1^{\star}$ & NA \\
\hline 12 & 0.56 & $0.25-1.18$ & 0.43 & $0.10-1.76$ & 1.03 & $0.56-1.88$ & 1 & NA \\
\hline $13-15$ & 0.33 & $0.15-0.72$ & 0.37 & $0.09-1.52$ & 0.63 & $0.34-1.16$ & 0.85 & $0.57-1.27$ \\
\hline$\geqslant 16$ & 0.20 & $0.07-0.57$ & 0.27 & $0.05-1.50$ & 0.43 & $0.21-0.89$ & 0.68 & $0.32-1.48$ \\
\hline \multicolumn{9}{|c|}{ Years of service } \\
\hline 1 & NA & NA & NA & NA & 1 & NA & 1 & NA \\
\hline 2 & NA & NA & NA & NA & 1.3 & $1.0-1.6$ & 0.94 & $0.56-1.56$ \\
\hline 3 & NA & NA & NA & NA & 1.5 & $1.2-2.0$ & 1.03 & $0.59-1.80$ \\
\hline 4 & NA & NA & NA & NA & 1.6 & $1.1-2.1$ & 0.66 & $0.35-1.26$ \\
\hline 5 & NA & NA & NA & NA & 1.6 & $1.1-2.2$ & 0.75 & $0.38-1.47$ \\
\hline
\end{tabular}

* The reference group for women on active duty was 12 years of education or less.

$\mathrm{OR}=$ odds ratios; $\mathrm{CI}=$ confidence intervals; $\mathrm{NA}=$ not applicable. 
Table 6 Statistically significant adjusted odds ratios for smokeless tobacco use by 18-34 year old recruits and men on active duty

\begin{tabular}{|c|c|c|c|c|}
\hline & \multicolumn{2}{|c|}{ Recruits } & \multicolumn{2}{|c|}{ Active duty } \\
\hline & $O R$ & $95 \% C I$ & $O R$ & $95 \% C I$ \\
\hline \multicolumn{5}{|l|}{ Race } \\
\hline White & 1 & NA & 1 & NA \\
\hline Black & 0.02 & $0.00-0.15$ & 0.06 & $0.04-0.11$ \\
\hline Hispanic & NA & NA & 0.19 & $0.11-0.32$ \\
\hline Asian & NA & NA & 0.33 & $0.13-0.83$ \\
\hline Others & 0.20 & $0.08-0.47$ & 0.78 & $0.40-1.52$ \\
\hline \multicolumn{5}{|l|}{ Service } \\
\hline Army & 1 & NA & 1 & NA \\
\hline Air force & 0.50 & $0.28-0.91$ & 0.36 & $0.28-0.45$ \\
\hline Marines & 1.92 & $1.13-3.26$ & 1.04 & $0.74-1.47$ \\
\hline Navy & 1.22 & $0.70-2.12$ & 0.53 & $0.42-0.67$ \\
\hline \multicolumn{5}{|l|}{ Home region } \\
\hline New England & 1 & NA & NA & NA \\
\hline Midwest & 3.09 & $1.3-7.2$ & NA & NA \\
\hline Southwest & 3.17 & $1.2-8.6$ & NA & NA \\
\hline West coast & 2.97 & $1.1-7.8$ & NA & NA \\
\hline Region 2 & 0.88 & $0.33-2.30$ & NA & NA \\
\hline Region 4 & 1.89 & $0.83-4.31$ & NA & NA \\
\hline Region 6 & 2.40 & $0.64-8.97$ & NA & NA \\
\hline Region 8 & 1.17 & $0.23-6.08$ & NA & NA \\
\hline \multicolumn{5}{|l|}{ Rank } \\
\hline E-1 & NA & NA & 1 & NA \\
\hline E-2 & NA & NA & 0.57 & $0.27-1.24$ \\
\hline E-3 & NA & NA & 0.51 & $0.25-1.03$ \\
\hline E-4 & NA & NA & 0.41 & $0.20-0.82$ \\
\hline E-5 & NA & NA & 0.52 & $0.25-1.08$ \\
\hline
\end{tabular}

$\mathrm{OR}=$ odds ratios; $\mathrm{CI}=$ confidence intervals; $\mathrm{NA}=$ not applicable.

SLT use quadrupled from $2.2 \%$ to $8.6 \%$ between recruit non-white/non-black men but remained unchanged, at near zero, for black men and for women of all races.

Tobacco use varied across branch of service (table 4). Navy personnel showed smaller gains in tobacco consumption between recruits and active duty than other military personnel.

Regression results for smoking (table 5) show that race is the only explanatory variable common to all four smoking models. Race is the only explanatory variable to stay in the smoking model for women on active duty.

Branch of service is retained as an explanatory variable in three of the four smoking models. For men, although navy recruits enter the service more likely to smoke than army recruits, and marine recruits are as likely as army recruits to smoke, sailors on active duty and marines are less likely to smoke than soldiers on active duty. In contrast, although both male air force recruits and personnel on active duty are less likely to smoke than their army counterparts, relatively more air force personnel on active duty smoke than air force recruits.

Among women, navy recruits are more likely, marine recruits are as likely, and air force recruits are less likely to smoke than army recruits. However, there is no difference in smoking prevalence across branch of service for personnel on active duty.

Where significant, higher education is associated with decreased smoking prevalence. Years of service on active duty is associated with increased smoking prevalence.

Table 6 shows SLT regression findings for men only because too few women used SLT to allow building SLT models for women. For both recruits and personnel on active duty, whites are much more likely to use SLT than other racial groups. Recruits from the midwest, southwest, and west coast are more likely to use SLT than recruits from elsewhere in the United States. Comparing non-army with army personnel, relatively fewer service members on active duty use SLT than recruits.

\section{Discussion}

The chief limitation of this study is its cross-sectional design. As such, causal conclusions cannot be drawn from the associations uncovered in the results. Nonetheless, cross-sectional studies can suggest causal hypothesis that can be tested with other study designs.

Overall, results from this study suggest, but do not prove, that exposure to the military leads to dramatic increases in tobacco use by young enlisted men, but not women. Further, increases in tobacco use are more likely to be found in the army than in the other services and among whites than among minorities.

The striking differential in smoking prevalence between genders in personnel on active duty is particularly noteworthy because no such differential exits in military recruits or in civilian society. Achieving gender parity in smoking prevalence in American civilians, largely the result of reducing smoking prevalence in men, took more than 30 years of government-supported public education and marketing. ${ }^{7}$ Military service somehow appears to undo these gains in as few as five years.

However, when inspecting the data more closely across age groups, we do not see an increase in tobacco use with increasing age. This suggests that there may be strong secular changes in smoking prevalence in military personnel on active duty that cannot be dissected out in this cross-sectional study.

These findings present a challenge and an opportunity. The challenge is to find ways to curb the initiation of tobacco use in male enlisted personnel. The opportunity is to explore and understand what causes the differential appeal of tobacco consumption across gender, race, and branch of service among enlisted service members so that effective tobacco control strategies might be devised. Also, the issues explored in this research need to be studied in officer personnel as well. Curbing tobacco use among military personnel should be a high priority to DoD for societal, economic, and readiness reasons.

From the societal perspective, tobacco use is the single most preventable cause of premature death in the United States, accounting for roughly $20 \%$ of all deaths annually. ${ }^{8}$ Many of these deaths follow costly, chronic, debilitating diseases, such as cardiovascular disease, respiratory illnesses, and various cancers that have been linked to tobacco use. ${ }^{9}$ Because fewer than 4\% of Americans die before age 35, smoking is not a major determinant of death between 17 and 35 years of age. ${ }^{10}$ Thus, the military medical system is unlikely to be burdened with many of the long-term cost consequences of service members' tobacco use. Nonetheless, these costs ultimately will be borne by society, including both the civilian and the Department of Veterans Affairs healthcare systems. Currently, 1.6 million men and 
women serve in the American armed forces with many of them re-entering civilian life after a short tour of duty. DoD has an obligation to the society from which it draws its members to return service members to civilian life as healthy and productive as possible.

Regarding economic self-interest, even though the military medical system may evade many of the long-term costs of tobacco use by service members, it will not avoid the short-term costs.

Smokers, on average, account for $18 \%$ more annual medical expenditures than non-smokers. ${ }^{10}$ Tobacco use has been linked to adverse pregnancy outcomes and to periodontal disease. ${ }^{911}$ These are excess costs that the military medical system can ill afford.

Tobacco consumption has an adverse impact on military readiness. Tobacco users have higher absenteeism, impaired perceptual and motor skills, and poorer endurance than non-tobacco users. ${ }^{10-14}$

DoD anti-smoking efforts already include a smoking ban in DoD buildings, a ban on access to tobacco during military recruit training, an increase in tobacco prices in military commissaries, as well as tobacco education and cessation programmes. Most of these efforts are aimed at punishing or changing the behaviour of current smokers. Because of the strong addictive qualities of tobacco, this approach can only have a limited effect on curbing tobacco use. A recent review of 188 randomised controlled trials on smoking cessation reveals that only $2 \%$ of all smokers successfully quit. ${ }^{15}$

More emphasis needs to be placed on convincing service members not to initiate tobacco use. This strategy will require a strong marketing approach that attempts to change favourable cultural attitudes toward tobacco within the military.

This paper was presented in a poster session at the annual scientific session of the Society of Behavioral Medicine in San Francisco, 16-19 April 1997. The views of the authors do not purport to reflect the views of the Department of the Army, the Department of the Navy, the Department of the Air Force, or the Department of Defense.

1 US Department of Defense. Survey of health related behaviors among military personnel. Report No RTI/6019/06-FR. among military personnel. Report No RTI/6019/06-FR. Research Triangle

2 Fletcher RH, Fletcher SW, Wagner EH. Clinical epidemiology: the essentials. 2nd ed. Baltimore, Maryland: Williams and Wilkins, 1988.

3 Cronan TA, Conway TL. Is the Navy attracting or creating smokers? Mil Med 1988;153:175-7.

4 Chisick MC, Arthur JS, York AK, et al. Designing a standardized oral health survey for the tri-services. Mil Med 1994;159:179-86.

5 Poindexter FR, York AK, Chisick MC, et al. A computer program for epidemiological data collection. Toward an electronic patient record '96. Proceedings of the twuelfth international symposium on the creation of an electronic health conference on patient cards. 1996;1:276-79.

6 Hosmer DW, Lemshow S. Applied logistic regression. New York: John Wiley, 1989.

7 Geronimus AT, Neidert LJ, Bound J. Age patterns of smoking in US black and white women of childbearing age. $\mathrm{Am}$ f Public Health 1993;83:1258-64.

8 Nelson DE, Kirdendall RS, Lawton RL, et al. Surveillance for smoking-attributable mortality and years of potential life lost, by state-United States, 1990. MMWR 1994; 43:1-8.

9 Fielding JE. Smoking: health effects and control. $N$ Engl $\mathcal{f}$ Med 1985;313:491-8.

0 Hodgson TA. Cigarette smoking and lifetime medical expenditures. Milbank $Q$ 1992;70:81-125.

11 Mandel I. Smoke signals: an alert for oral disease. 7 Am Dent Assoc 1994;125:872-8.

12 Cooper KH, Gey GO, Bottenberg RA. Effects of cigarette smoking on endurance performance. $7 A M A$ 1968; 203:123-6.

13 Bahrke MS, Baur TS, Poland DF, et al. Tobacco use and performance on the US Army physical fitness test. Mil
Med 1988;153:229-35.

14 Jensen RG. The effect of cigarette smoking on Army physical readiness test performance of enlisted Army Medical cal readiness test performance of enlisted Army

15 Law M, Tang JL. An analysis of the effectiveness of interventions intended to help people stop smoking. Arch Intern Med 1995;155:1933-41. 